\title{
Lateral Habenula Involvement in Impulsive Cocaine Seeking
}

\author{
Agustin Zapata', Eun-Kyung Hwang' and Carl R Lupica*, I \\ 'Electrophysiology Research Section, Cellular Neurobiology Branch, National Institutes of Health, National Institute on Drug Abuse, Intramural \\ Research Program, Baltimore, MD, USA
}

\begin{abstract}
The lateral habenula $(\mathrm{LHb})$ is a brain structure receiving inputs from limbic forebrain areas and innervating major midbrain monoaminergic nuclei. Evidence indicates LHb involvement in sleep control, reward-based decision making, avoidance of punishment, and responses to stress. Additional work has established that the LHb mediates negative feedback in response to aversive events. As a hallmark of drug addiction is the inability to limit drug use despite negative consequences, we hypothesize that LHb dysfunction may have a role in the lack of control over drug seeking. Here we examine the effects of LHb inactivation in control over drug seeking in several cocaine selfadministration (SA) paradigms in rats. We find that inhibition of the LHb with GABAergic agonists did not alter cocaine SA under progressive ratio or seeking/taking chained reinforcement schedules, or during punishment-induced suppression of cocaine-reinforced responding. In contrast, LHb inhibition increased cocaine seeking when the drug was not available in rats trained to discriminate its presence using an environmental cue. This effect of LHb inhibition was selective for cocaine, as it did not impair responding for sucrose reinforcement. The effect of LHb injection of GABA agonists was mimicked by intra-LHb muscarinic cholinergic (mACh) antagonist injection, and activation of $\mathrm{mACh}$ receptors excited a majority of $\mathrm{LHb}$ neurons in in vitro electrophysiology experiments. These results indicate that the LHb participates in the suppression of impulsive responding for cocaine through the activation of a cholinergic circuit, and they suggest that LHb dysfunction may contribute to impaired impulse control associated with drug addiction. Neuropsychopharmacology (2017) 42, I I03-III2; doi: I0.1038/npp.2016.286; published online I 8 January 2017
\end{abstract}

\section{INTRODUCTION}

The habenular complex constitutes a major relay between the forebrain and midbrain/hindbrain areas (Lecourtier and Kelly, 2007; Sutherland, 1982). Two major subdivisions have been identified based on anatomical connectivity and cellular composition: the lateral and the medial habenula ( $\mathrm{LHb}$ and $\mathrm{MHb}$, respectively). The $\mathrm{LHb}$ receives input from the limbic forebrain and basal ganglia and influences the activity of all major mid-brain monoaminergic nuclei. As LHb neurons are activated by negative outcomes, such as punishment, omission of an expected reward, or stimuli associated with negative events, it is suggested that a primary role is to process negative feedback associated with reward seeking behavior (Matsumoto and Hikosaka, 2007, 2009). Consistent with this, activation of the LHb strongly inhibits dopamine (DA) neurons of the ventral tegmental area (VTA), a central component of the brain's reward pathway (Christoph et al, 1986; Ji and Shepard, 2007; Matsumoto and Hikosaka, 2007). However, this inhibition of DA neurons is indirect, involving LHb-mediated excitation of inhibitory neurons in the rostromedial tegmental area (RMTg), that broadly innervate

*Correspondence: Dr C Lupica, Electrophysiology Research Section, Cellular Neurobiology Branch, National Institutes of Health, National Institute on Drug Abuse, Intramural Research Program, Baltimore, MD 21224, USA, Tel: + 443740 2824, E-mail: clupica@mail.nih.gov

Received I6 September 2016 ; revised 13 December 20 I6; accepted 19 December 2016; accepted article preview online 27 December 2016 the VTA DA neurons (Hong et al, 2011; Jhou et al, 2009). As optogenetic activation of the LHb to RMTg pathway is aversive (Stamatakis and Stuber, 2012), it is proposed that regulation of VTA DA activity by the $\mathrm{LHb}$ may underlie aversive effects of abused drugs (Lecca et al, 2014; Velasquez et al, 2014). Consistent with this, LHb neurons are influenced by cocaine (Good et al, 2013; Jhou et al, 2013; Maroteaux and Mameli, 2012; Zuo et al, 2013), and LHb activation is linked to the delayed aversive effects of cocaine (Jhou et al, 2013), as well as to the negative, depressive-like state that occurs after chronic cocaine (Meye et al, 2015). However, evidence for involvement of the $\mathrm{LHb}$ in ongoing drug-seeking behavior is limited (Lecca et al, 2014; Velasquez et al, 2014). As the LHb is associated with the aversive properties of abused drugs (Jhou et al, 2013) and the suppression of behavior leading to negative outcomes (Hikosaka, 2010), we hypothesize that it may be involved in regulating excessive or inappropriate drug-seeking behavior seen in addiction, where drug seeking persists despite its adverse consequences.

Previous studies have used animal behavioral paradigms to model diagnostic criteria of addiction in humans (BelinRauscent et al, 2016; Vanderschuren and Ahmed, 2013). We have adapted rat cocaine SA paradigms (Deroche-Gamonet et al, 2004; Pelloux et al, 2007; Vanderschuren and Everitt, 2004) to examine whether LHb inhibition alters: (i) motivation to seek cocaine measured by break points in a progressive ratio (PR) schedule; (ii) the persistence of cocaine seeking during punishment of cocaine-reinforced responding; or (iii) the ability to control cocaine seeking 
during alternating periods of signaled availability and nonavailability (Go/NoGo task). We find that $\mathrm{LHb}$ inhibition increases cocaine seeking when cocaine is not available in a Go/NoGo paradigm, suggesting impaired control over drug seeking.

\section{MATERIALS AND METHODS}

\section{Subjects}

Male Long Evans rats (Charles River Laboratories, Wilmington, MA) weighing 300-400 $\mathrm{g}$ at the beginning of experiments were housed $2-3$ per cage in facilities accredited by the American Association for the Accreditation of Laboratory Animal Care. They were maintained in a temperature- and humidity-controlled environment, under a reverse $12 \mathrm{~h}$ light/ dark cycle, with ad libitum food and water. All behavioral experiments were conducted during the dark cycle. The experimental procedures were approved by the Institutional Care and Use Committee of the National Institute on Drug Abuse, National Institutes of Health (Rockville, MD) and conducted in accordance with the Guide for the Care and Use of Laboratory Animals provided by the NIH and adopted by the NIDA Intramural Research Program.

\section{Surgery}

Rats were anesthetized with Equithesin (1\% pentobarbital, $2 \%$ magnesium sulfate, $4 \%$ chloral hydrate, $42 \%$ propyleneglycol, $11 \%$ ethanol, $3 \mathrm{ml} / \mathrm{kg}$ i.p.), and a silastic catheter (ID: 0.020" OD: 0.037", Dow Corning, MI) was advanced $3.5 \mathrm{~cm}$ into the right jugular vein. The catheter terminated in an L-shaped steel tube mounted on top of the skull with cranioplastic cement and was secured with three stainless steel screws. In the same surgery, subjects were stereotaxically implanted with bilateral guide cannulae (C315, Plastics One, Roanoke, VA) aimed $1 \mathrm{~mm}$ dorsal to the LHb (AP: $-3.6, \mathrm{~L}: \pm 0.6, \mathrm{~V}:-3.6 \mathrm{~mm}$ relative to bregma). Following surgery, rats were housed individually and allowed to recover for at least 1 week prior to beginning experiments. Catheters were flushed after every training session with $0.1 \mathrm{ml}$ of heparinized saline and $120 \mathrm{mg} / \mathrm{ml}$ cefazolin throughout the study.

\section{Behavioral Procedures}

Operant training took place in standard rat operant chambers (Med-Associates; St Albans, VT) placed inside sound attenuated boxes and equipped with a wall-mounted ventilation fan that provided background noise. A liquid swivel was mounted above the operant box to allow for connecting the IV catheters via PE50 tubing to an infusion pump located outside the chamber. The operant boxes were equipped with liquid dippers able to dispense $10 \mu \mathrm{l}$ of a liquid solution to a magazine situated between two retractable levers. A light was located above each lever and a house light was placed on the opposite wall.

Experiment 1. Rats were trained on a drug-seeking/taking chained schedule of cocaine self-administration (Zapata et al, 2010) in which they were required to press one lever (taking lever) to receive an i.v. cocaine infusion $(0.75 \mathrm{mg} / \mathrm{kg} /$ infusion) under a fixed ratio 1 (FR1) schedule (Zapata et al, 2010). Following each response, the taking lever was retracted and the house light extinguished, followed by illumination of a cue light above the taking lever for $30 \mathrm{~s}$. Animals were allowed to self-administer for a maximum of 40 infusions or $2 \mathrm{~h}$. A chained schedule was then initiated in which every infusion cycle started with the insertion of a second lever, designated as the drug-seeking lever. The first lever press on the seeking lever after completion of a random interval ( $2 \mathrm{~s}$ average, RI2) resulted in retraction of the seeking lever and extension of the taking lever. The next press of the taking lever resulted in the cocaine infusion sequence. A time out of $30 \mathrm{~s}$ (TO30) was imposed after every infusion, after which another infusion cycle started with the presentation of the drug-seeking lever. Thus rats self-administered cocaine under an RI2/FR1:TO30 chained cocaine seeking/taking schedule. Each daily session lasted for $2 \mathrm{~h}$ or 10 infusions. The RI and TO components of the chained schedule were then increased in the following steps; RI2/FR1:TO30, RI20/ FR1:TO120, RI60/FR1:TO300, RI120/FR1:TO600. After stable responding on the final chained schedule was achieved, motivation for the drug was tested in two drugseeking/taking sessions alternating with two sessions in which only the taking lever was present and cocaine was available under a PR schedule.

Intracranial infusion of drugs was carried out using a microinjection cannula (C315I, Plastics One) inserted into the surgically implanted guide cannula and extended $1.0 \mathrm{~mm}$ below its tip. One of the solutions $(0.5 \mu \mathrm{l})$ was then infused at a rate of $1 \mu \mathrm{l} / \mathrm{min}$. The microinjection cannula was removed 1 min after the infusion, and animals were then placed in the operant boxes. In Experiment 1, rats received either phosphate-buffered saline (PBS) or Baclofen/Muscimol $(\mathrm{B} / \mathrm{M}, 1 \mathrm{mM} / 0.1 \mathrm{mM})$ infused bilaterally in the LHb immediately before each test session, and each animal was tested with both $\mathrm{PBS}$ and $\mathrm{B} / \mathrm{M}$ in each test condition, in a random order, according to a within-subject repeatedmeasures design.

During PR schedule sessions, only the drug-taking lever was present and each infusion resulted in an increase in the response ratio requirement for the next infusion (Richardson and Roberts, 1996). The PR session was terminated when the animal failed to earn an infusion for $60 \mathrm{~min}$. The last ratio completed was considered the breakpoint and was recorded as a measure of the animal's motivation to seek the drug. During the seeking/taking chained schedule sessions, the seeking responses were recorded as an additional measure of motivation for the drug thought to be less influenced by the non-specific motor enhancing effects of psychostimulants (Olmstead et al, 2000).

After testing for drug motivation, rats were given three sessions on the RI120/FR1:TO600 chained schedule, followed by five punished sessions in which a response on the seeking lever resulted in either access to the taking lever or a scrambled foot shock delivered through the floor grid $(50 \%$ probability, $0.6 \mathrm{~mA} \times 0.5 \mathrm{~s}$ ). One group of animals received $\mathrm{PBS}$ and the other $\mathrm{B} / \mathrm{M}$ infusions in the LHb before each session in a between-subject design.

Experiment 2. Rats self-administered cocaine for 12 sessions ( $2 \mathrm{~h}$ or 40 infusions per session) on an FR1 
schedule. Then they were trained on a Go-NoGo task consisting of $2 \mathrm{~h}$ sessions comprised of $620 \mathrm{~min}$ alternating intervals of cocaine availability (Go)/non-availability (NoGo), signaled by the house light (light on during cocaine availability). During Go intervals, responses were reinforced with cocaine under an FR5 schedule, and during NoGo intervals, lever responses did not trigger cocaine infusions. The number of lever responses during the 3 Go and 3 NoGo intervals in each session was recorded. Training progressed until stable discrimination of the Go-NoGo intervals was observed (3 consecutive sessions in which NoGo responses were $<30 \%$ of total, $12-14$ sessions). After reaching criterion, each rat received bilateral infusions of $\mathrm{PBS}$ or $\mathrm{B} /$ $\mathrm{M}$ in the $\mathrm{LHb}$, in a randomized order, immediately before each test session. Sessions were counterbalanced such that some started with a Go period, while other began with a NoGo interval to control for the motor stimulant effects of cocaine.

Following testing on the Go-NoGo task, rats were retrained on an FR1 schedule and tested for sensitivity to punished responding for cocaine self-administration. They were divided into two groups, one group receiving bilateral $\mathrm{LHb}$ infusions of PBS and the other $\mathrm{B} / \mathrm{M}$ prior to each session. Rats completed 3 baseline sessions, followed by 3 punished sessions in which cocaine infusions were accompanied by a scrambled foot shock $30 \%$ of the time $(0.6 \mathrm{~mA} \times 1 \mathrm{~s})$.

Experiment 3. Groups of rats were trained to selfadminister cocaine in the Go-NoGo task. Then the effects of bilateral LHb infusion of one of the several neurotransmitter receptor antagonists was investigated. Each group received vehicle, $\mathrm{B} / \mathrm{M}$, or one of the two additional drugs on different test days in random order. These included the nonselective DA receptor antagonist flupenthixol $(60 \mathrm{mM})$, the non-selective ionotropic glutamate receptor antagonist kynurenic acid (KA; $50 \mathrm{mM}$ ), a mixture of the 5-HT receptor antagonists ritanserin/ondansetron $(5 \mathrm{mM} / 5 \mathrm{mM}$ in $10 \%$ DMSO), the $\beta$-subunit-containing nicotinic acetylcholine (ACh) receptor antagonist mecamylamine $(100 \mathrm{mM})$, or the non-selective muscarinic ACh (mACh) antagonist scopolamine $(50 \mathrm{mM})$. The concentrations of all antagonists used in these experiments were chosen based on previous literature (de Mello Cruz et al, 2005; Murray et al, 2012; Santini et al, 2012; Sun et al, 2005; Tuerke et al, 2012; Wickham et al, 2013).

\section{Experiment 4}

In vitro patch clamp electrophysiology. Brain slices were prepared from 10 -week-old rats using a vibrating tissue slicer (Leica VT1000S) according to previously published protocols (Jhou et al, 2013). Coronal slices $(280 \mu \mathrm{m})$ containing the $\mathrm{LHb}$ were transferred to a holding chamber containing normal aCSF consisting of (mM): $\mathrm{NaCl}, 126 ; \mathrm{KCl}$, 3.0; $\mathrm{MgCl}_{2}, 1.5 ; \mathrm{CaCl}_{2}, 2.4 ; \mathrm{NaH}_{2} \mathrm{PO}_{4}, 1.2 ;$ glucose, 11.0; $\mathrm{NaHCO}_{3}, 26$, saturated with $95 \% \mathrm{O}_{2} / 5 \% \mathrm{CO}_{2}$, at $35^{\circ} \mathrm{C}$ for 20-25 min, maintained at room temperature. A brain slice was submerged in a low-volume $(170 \mu \mathrm{l})$ recording chamber integrated into a fixed stage of an upright microscope and continuously perfused with warm $\left(30-32^{\circ} \mathrm{C}\right)$ aCSF at $2 \mathrm{ml} /$ min using a peristaltic pump. The aCSF was warmed using an inline solution heater (TC-324B, Warner Instruments). Drugs were prepared as stock solutions in $\mathrm{H}_{2} \mathrm{O}$ and diluted in aCSF to the indicated concentrations. Visualization of $\mathrm{LHb}$ neurons was performed using differential interference contrast microscopy (Zeiss Axioskop). Recording electrodes (3-5 M $\Omega$ ) were filled with (in $\mathrm{mM}$ ): K-gluconate, 140; KCl, 5; HEPES, 10; EGTA, 0.2; $\mathrm{MgCl}_{2}, 2$; Mg-ATP, 4; $\mathrm{Na}_{2}$-GTP, 0.3; $\mathrm{Na}_{2}$-phosphocreatine, 10; pH 7.2 with KOH. Whole-cell voltage clamp recordings were performed using an Axopatch 200B (Molecular Devices), WinLTP software (WinLTP Ltd), and an A/D board (National Instruments PCI-6251) residing in a personal computer. Series resistance was monitored throughout recordings using brief hyperpolarizing steps $(-10 \mathrm{mV}, 200 \mathrm{~ms})$, and cells demonstrating $>10 \%$ change were excluded from analyses. Unless otherwise indicated, cells were voltage clamped at $-60 \mathrm{mV}$.

Drug application to $\mathrm{LHb}$ slices. Oxotremorine-M (Oxo$\mathrm{M})$ and scopolamine were purchased from Tocris Bioscience (Bristol, UK), dissolved at their final concentrations in normal aCSF and delivered to the brain slices via the peristaltic pump used for bath perfusion.

Experiment 5. A group of drug-naive rats was trained to respond for sucrose solution reward (10 $\mu$ l of $20 \%$ sucrose) obtained via a dipper cup located in the food magazine. Lever presses on the active lever resulted in refilling of the dipper cup, followed by retraction of both levers and illumination of a cue light above the active lever for $5 \mathrm{~s}$. Animals were trained under FR1 for a single 6-h session and then switched to $2 \mathrm{~h}$ long sessions or until 600 reinforcers were obtained. After 10 sessions, animals were switched to a Go-NoGo schedule $(3 \times 20 \mathrm{~min}$ intervals of food access interspersed with $3 \times 20 \mathrm{~min}$ of sucrose unavailability, signaled by house light on or off, respectively). After stable responding was achieved (10-12 sessions), animals received bilateral infusions of either PBS or $\mathrm{B} / \mathrm{M}$ in the $\mathrm{LHb}$ immediately before each daily session. Treatments were given over consecutive testing sessions in a random order in a within-subject design.

\section{Histology}

At the end of the experiment, cresyl violet $(1 \% \times 0.5 \mu \mathrm{l})$ was bilaterally infused through the guide cannulae. The animals were then killed, and their brains were removed and frozen on dry ice. Histological verification of the microinjection site was carried out in $30 \mu \mathrm{m}$ cryostat frozen sections.

\section{Data Analysis}

Statistical analysis was conducted using one- or two-way repeated-measures ANOVA (GraphPad Software, La Jolla, CA). Main factors were training session/condition and treatment (LHb intracranial infusion). Differences among groups were assessed by Holms-Sidak's multiple comparison tests. An alpha value of $p<0.05$ was considered statistically significant. 
a

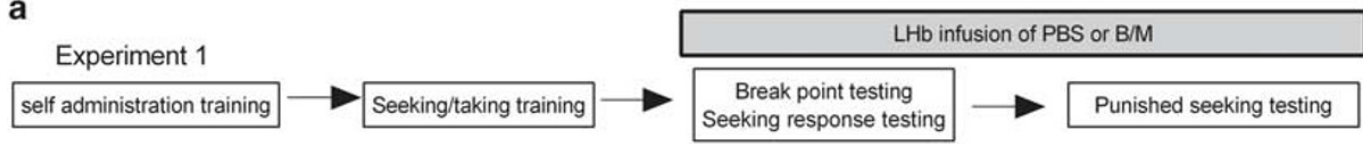

$\begin{array}{ll}\text { Experiment } 2 & \text { LHb infusion of PBS or B/M } \\ \text { self administration training } \longrightarrow \text { Go/NoGo training } \rightarrow \text { Go/NoGo testing } & \text { Punished responding testing }\end{array}$

b

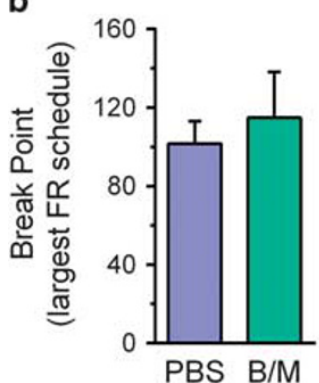

C

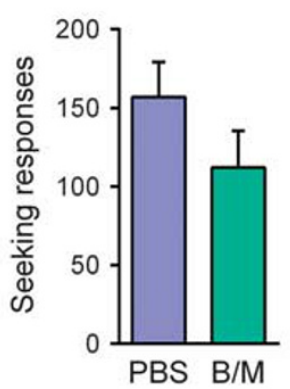

\section{d}

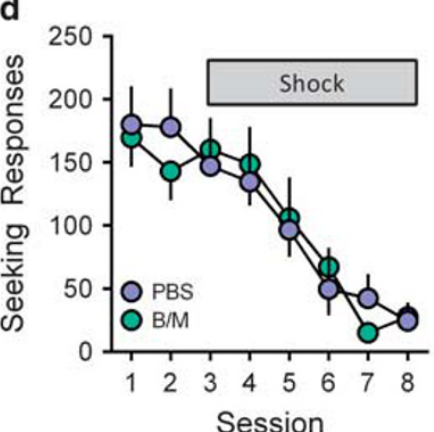

e

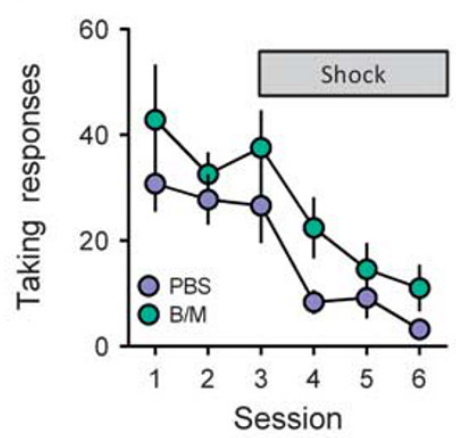

f

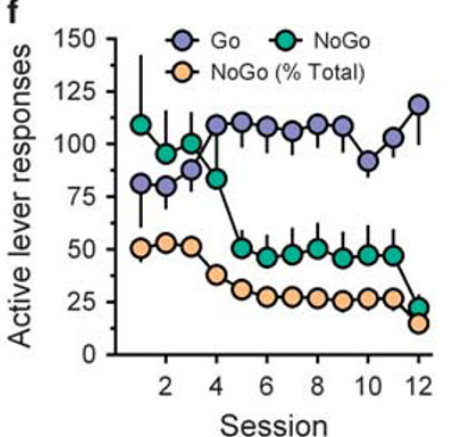

g

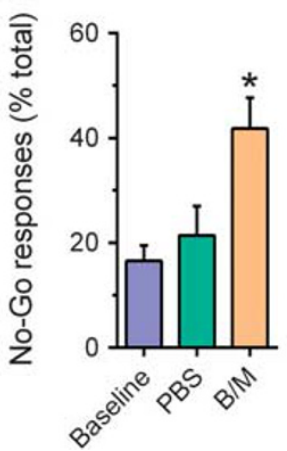

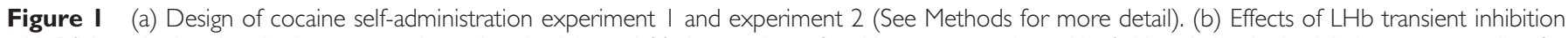

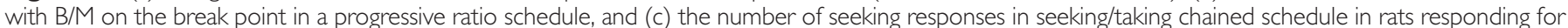

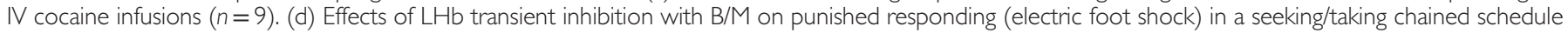

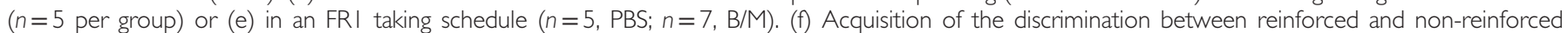

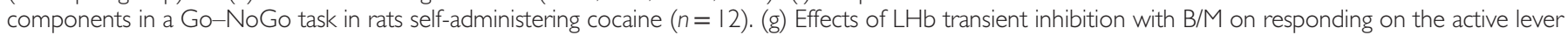
during NoGo intervals ( $* 0<0.05$ vs PBS control, paired t-test, $n=12$ ). All data are mean \pm SEM.

\section{RESULTS}

Histological examination of the injection sites showed that most infusions were made in the LHb, mainly in its medial aspect (Supplementary Figure S1). Only animals with a confirmed $\mathrm{LHb}$ infusion site were included in the data analysis.

\section{Experiment 1: Inactivation of the LHb Does not Alter Motivation for Cocaine or Punished Responding for Cocaine}

The sequence for experiment 1 is shown in Figure 1a. The effect of $\mathrm{LHb}$ inhibition with $\mathrm{B} / \mathrm{M}$ was examined on cocaineseeking behavior using a PR schedule of cocaine reinforcement. Bilateral $\mathrm{B} / \mathrm{M}$ infusions did not significantly alter the maximum number of responses emitted to receive cocaine reinforcement (break point) $\left(t_{(8)}=0.51, p=0.62\right.$, paired $t$-test, Figure $1 \mathrm{~b})$ nor the number of responses in the seeking link of a seeking/taking chained schedule $\left(t_{(8)}=1.4, p=0.20\right.$, paired $t$-test, Figure 1c).

We next evaluated whether LHb inhibition altered punished suppression of responding for cocaine by pairing seeking responses with foot shock in $50 \%$ of these trials. The punishment caused a significant decrease in subsequent seeking responses in both groups (main effect of punishment, $\mathrm{F}_{(7,56)}=17.70, p<0.0001$, ANOVA, Figure 1d). However, inhibition of the $\mathrm{LHb}$ by $\mathrm{B} / \mathrm{M}$ did not alter this effect (no main $\mathrm{B} / \mathrm{M}$ treatment effect nor punishment by treatment interaction, $\mathrm{F}_{(1,8)}=0, p=0.95$ and $\mathrm{F}_{(7,56)}=0.48, p=0.84$, respectively). In an alternative punishment paradigm in which cocaine-taking responses were paired with foot shock, there was also decreased responding $\left(\mathrm{F}_{(5,50)}=10.0\right.$, $p<0.0001$, ANOVA, Figure 1e). However, the suppression of taking responses by punishment was also not altered by $\mathrm{LHb}$ inhibition (no main $\mathrm{B} / \mathrm{M}$ treatment effect nor punishment by treatment interaction, $\mathrm{F}_{(1,10)}=2.80, p=0.12$ and $\mathrm{F}_{(5,50)}=0.26, p=0.93$, respectively). These data suggest that $\mathrm{LHb}$ inactivation does not alter the motivation to seek 
cocaine nor the suppression of cocaine seeking by punishment.

\section{Experiment 2. Persistence of Cocaine Seeking Despite its Signaled Unavailability After LHb Inhibition}

The inability to refrain from drug seeking is a hallmark of addiction that can be modeled in rodents by testing their ability to withhold responding during signaled periods when the drug is not available (Belin et al, 2008; Deroche-Gamonet et al, 2004). We examined a role for the LHb in withholding responses for cocaine using a Go-NoGo task. During training, the percentage of incorrect responses emitted when cocaine was not available (NoGo) declined significantly from $50.4 \%$ on day 1 to $14.8 \%$ on day $12 \quad\left(\mathrm{~F}_{(11,121)}=6.740\right.$, $p=0.0001$, one way ANOVA, Figure 1f). This resulted from decreased responding during NoGo periods $\left(\mathrm{F}_{(11,121)}=3.07\right.$, $p=0.04$, one way ANOVA, Figure 1f), with no change in responding during the Go intervals $\left(\mathrm{F}_{(11,121)}=1.68, p=0.16\right)$. $\mathrm{LHb}$ inactivation with $\mathrm{B} / \mathrm{M}$ disrupted this learned discrimination, resulting in significantly increased cocaine-seeking responses during the NoGo period $(\mathrm{PBS}=21.4,9.1-33.8$; $\mathrm{B} / \mathrm{M}=41.8,29.0-54.7$, mean and $95 \%$ confidence intervals; $t_{(11)}=3.061, p=0.01$, paired $t$-test, Figure 1g). Detailed analysis revealed that $\mathrm{B} / \mathrm{M}$ infusions enhanced responding during NoGo intervals, without significantly altering responding during Go intervals (significant main effect of Go-NoGo intervals, $\mathrm{F}_{(1,11)}=16.74, p<0.002$; and intervals $\times$ $\mathrm{LHb}$ infusion interaction, $\mathrm{F}_{(1,11)}=5.09, p=0.045$, two way ANOVA, Figure 2a). We also observed a non-significant
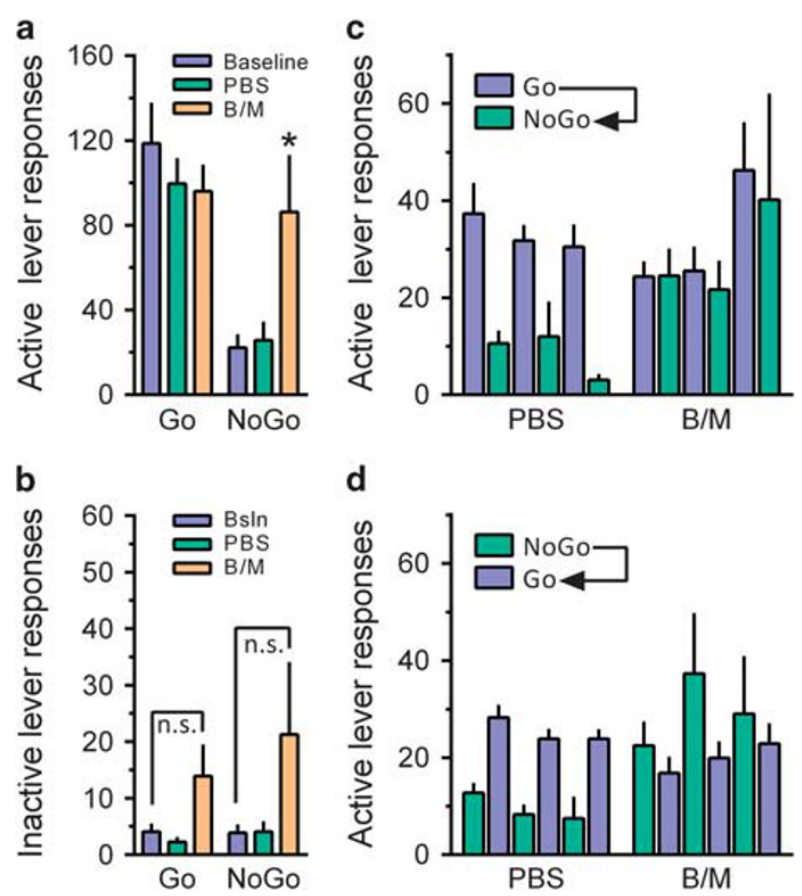

Figure 2 Effects of $\mathrm{LHb}$ transient inactivation on the total number of responses on the active (a) or inactive (b) lever during the Go and No-Go intervals ( $p<0.05$ vs PBS control, Holm-Sidak's test, $n=12$ ). (c) Active lever responses during each consecutive $20 \mathrm{~min}$ alternating Go-NoGo periods, starting the session with a Go or NoGo (d) interval, after PBS or $\mathrm{B} / \mathrm{M}$ infusion in the $\mathrm{LHb}(n=12$ in both experiments). All data are mean \pm SEM. (main effect of LHb infusion, $\mathrm{F}_{(1,10)}=2.52, p=0.14$, two way ANOVA) trend toward increased responding on the inactive lever after $\mathrm{B} / \mathrm{M}$ infusions (Figure $2 \mathrm{~b}$ ) during both $\mathrm{Go}$ and NoGo intervals (non-significant $\mathrm{LHb}$ infusion $\times$ intervals interaction, $\mathrm{F}_{(1,10)}=0.39, p=0.55$, two-way ANOVA).

We next determined whether the effect of $\mathrm{B} / \mathrm{M}$ on NoGo responding was present across all 3,20 min periods in the test session. A three-way ANOVA with LHb infusion, Go-NoGo condition, and interval order as main factors revealed a significant Go-NoGo $\times$ LHb infusion interaction $\left(\mathrm{F}_{(1,132)}=5.08, p=0.03\right)$, with no significant effect of interval order $\left(\mathrm{F}_{(2,132)}=0.88, p=0.42\right)$ nor interval order $\times$ Go-NoGo $\times$ LHb infusion $\left(\mathrm{F}_{(2,132)}=0.11, p=0.89\right)$, indicating that the enhanced cocaine-seeking responses during the NoGo intervals was present throughout the entire test session (Figure 2c).

In the design above, all NoGo intervals were preceded by Go intervals in which cocaine was self-administered, perhaps leading to a confound in which the continued responding during NoGo periods resulted from cocaineassociated motor stimulation. To test this, the order of the Go-NoGo intervals was reversed, and sessions begun with a NoGo interval in which responding was measured before cocaine exposure. However, even with reversal of Go-NoGo order, responding for cocaine was still significantly elevated during NoGo trials (Figure 2d, significant Go-NoGo $\times$ LHb infusion interaction, $\mathrm{F}_{(1,132)}=14.5$, $p<0.001$, three-way ANOVA). Importantly, the interval order did not influence this effect (non-significant interval order effect, $\mathrm{F}_{(2,132)}=0.16, p=0.85$ nor interval order $\times$ GoNoGo $\times$ LHb infusion interaction $\left(\mathrm{F}_{(2,132)}=0.31, p=0.73\right.$, Figure $2 \mathrm{~d}$ ), indicating that exposure to cocaine during the Go intervals did not influence responding during NoGo intervals.

To control for diffusion of $\mathrm{B} / \mathrm{M}$ into brain areas dorsal to the $\mathrm{LHb}$, we implanted cannulae with tips located $1 \mathrm{~mm}$ above the LHb and tested the effects of either the GABA agonists or PBS on the GoNoGo task $(n=4)$. Infusions of $\mathrm{B} / \mathrm{M}$ at this anatomical site did not significantly modify NoGo responding $\left(t_{(3)}=0.58, p=0.60\right.$, paired $t$-test, Supplementary Figure S2) compared with PBS, suggesting that diffusion of $\mathrm{B} / \mathrm{M}$ up the infusion track to areas dorsal to the $\mathrm{LHb}$ did not account for the pattern of results observed with intra-LHb infusions.

\section{Experiment 3. Go-NoGo Deficits are Mimicked by $\mathrm{mACh}$ Receptor Antagonism}

We next investigated the neurotransmitter pathways that may underlie LHb control of cocaine seeking during NoGo periods. Local LHb blockade of ionotropic excitatory aminoacid receptors with $\mathrm{KA}(50 \mathrm{mM})$, or D1 and D2 DA receptors with flupenthixol $(60 \mathrm{mM})$, did not alter cocaine seeking in the Go-NoGo procedure (Figure 3a). Similarly, blockade of $5-\mathrm{HT}_{2}$ or $5-\mathrm{HT}_{3}$ receptors with ritanserin and ondansetron (5 $\mathrm{mM}$ each), respectively, did not alter responding (Figure $3 \mathrm{~b}$ ). To investigate the involvement of cholinergic receptors, we tested the $\beta$-subunit nACh receptor antagonist mecamylamine $(100 \mathrm{mM})$, which did not alter responding during NoGo intervals. In contrast to these negative results, intra-LHb infusion of the $\mathrm{mACh}$ receptor antagonist scopolamine $(50 \mathrm{mM})$ significantly increased 

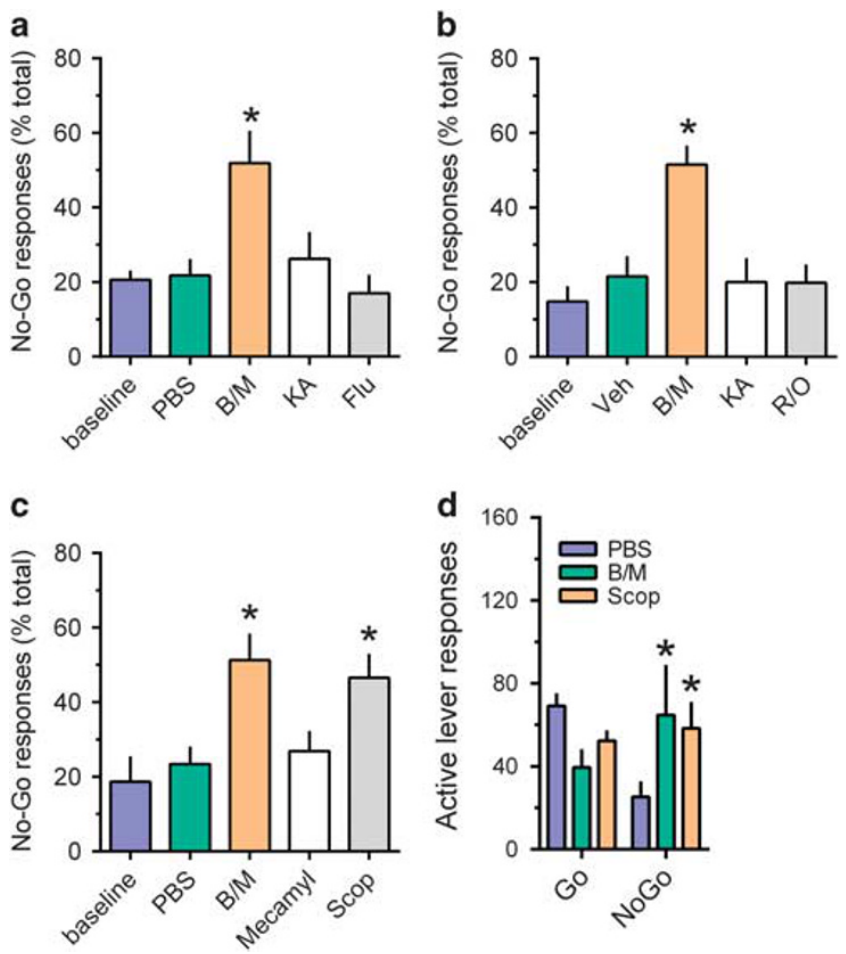

Figure 3 Effects of $\mathrm{LHb}$ infusion of receptor antagonists on responding during the NoGo intervals. (a) Effects of the ionotropic glutamate receptor antagonist kynurenic acid (KA, $50 \mathrm{mM}$ ) and the dopamine antagonist flupenthixol (Flu, $60 \mathrm{mM}$ ), compared with the effects of PBS and B/M (I mM/O.I mM). $n=8$ for all groups. (b) Effects of KA $(50 \mathrm{mM})$ and the combination $5 \mathrm{HT}_{2 / 3}$ antagonist ritanserin/ondansetron ( $\mathrm{R} / \mathrm{O}, 5 \mathrm{mM}$ each), $n=7$ for all groups. (c) Effects of the nicotinic antagonist mecamylamine (Mecamyl, $100 \mathrm{mM}$ ) and the muscarinic antagonist scopolamine (Scop, $50 \mathrm{mM}$ ), $n=1$ I for all groups. (d) Effects of LHb scopolamine infusions on the total number of responses during the NoGo and Go intervals $(n=\mid I)$. All data are mean \pm SEM (* $p<0.05$ vs vehicle group, Holm-Sidak's test).

cocaine-seeking responses during NoGo intervals $\left(\mathrm{F}_{(2,25)}=6.21, p=0.004\right.$, ANOVA, $p=0.02$ vs PBS, HolmsSidak's post hoc test, Figure 3c). Further analysis revealed that scopolamine selectively increased responding during NoGo intervals without affecting responses during Go intervals (significant LHb infusion $\times$ Go-NoGo interaction, $\mathrm{F}_{(2,20)}=5.794, p=0.01$, two way ANOVA, Figure 3d).

\section{Experiment 4. mACh Receptor-Induced Excitation of LHb Neurons In Vitro}

Our observation that $\mathrm{B} / \mathrm{M}$ infusions into the $\mathrm{LHb}$ disrupt Go-NoGo responding for cocaine imply that increased activity of these neurons is required for this discrimination. This, together with the results with scopolamine, led us to hypothesize that $\mathrm{mACh}$ receptor activation excites $\mathrm{LHb}$ neurons. To test this, whole-cell patch clamp recordings were obtained from LHb neurons in brain slices and the effects of the mACh agonist Oxo-M on the amount of current necessary to hold the neuronal membrane potential ( $\left.I_{\text {hold }}\right)$ at $-60 \mathrm{mV}$ was examined. Most LHB neurons (50\%) exhibited a decrease in $I_{\text {hold }}$ upon application of Oxo-M $(10 \mu \mathrm{M}$; Figure 4$)$, which is consistent with the activation of monophasic depolarizing inward currents. The remaining a

1

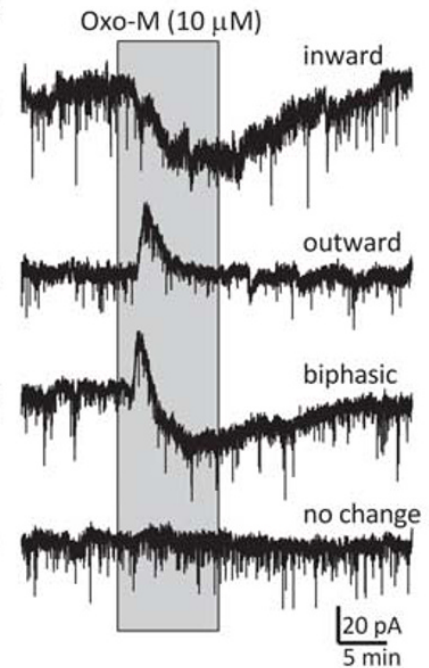

b
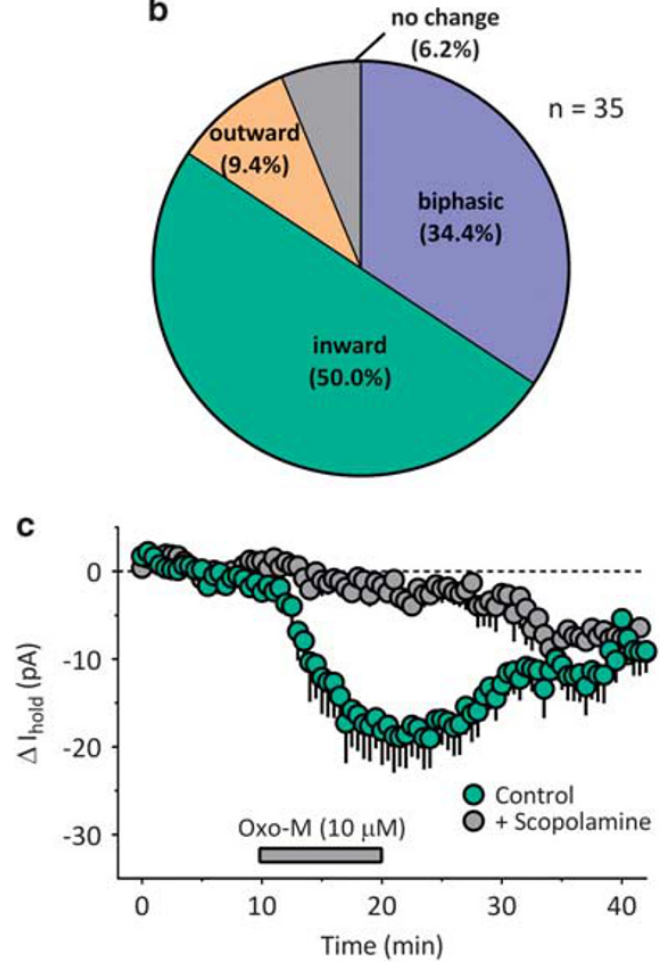

Figure 4 Muscarinic acetylcholine ( $\mathrm{mACh}$ ) receptor control of $\mathrm{LH} b$ neurons. (a) Representative examples of four distinct membrane current responses that were observed upon application of mACh receptor agonist (oxotremorine-M (Oxo-M) IO MM) in four different LHb neurons. The recordings were made in brain slices with neuronal membrane potentials voltage clamped at $-60 \mathrm{mV}$. After stable baseline membrane current was observed for at least $10 \mathrm{~min}$, Oxo-M was applied for 10 min (gray vertical bar) and membrane current was recorded for the next 20 min. (b) Proportion of $\mathrm{LHb}$ neurons displaying each of four different responses to bath-applied Oxo-M in in vitro voltage clamp experiments. These responses to Oxo-M included excitatory inward currents, inhibitory outward currents, biphasic outward-inward currents, and no change in membrane current. Note that inward depolarizing currents were most frequently observed upon Oxo-M application. (c) The non-selective mACh receptor antagonist scopolamine ( $10 \mu \mathrm{M}, n=1 \mid$ neurons) prevents inward currents initiated by Oxo-M ( $n=35$ neurons) 
a

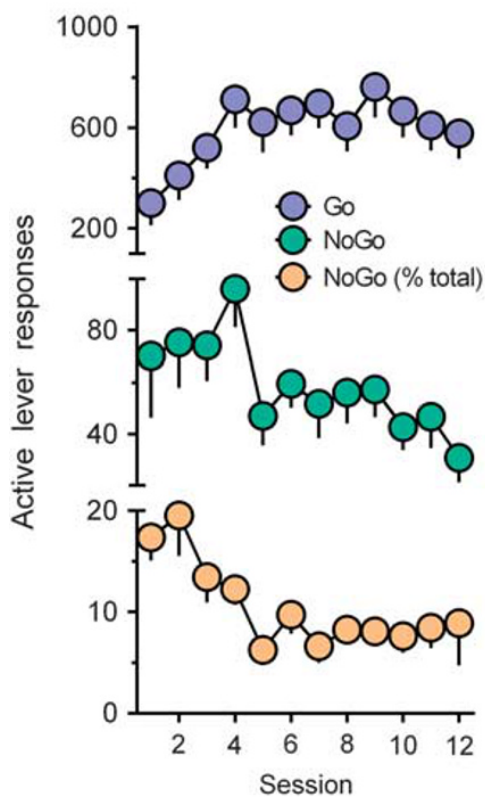

b



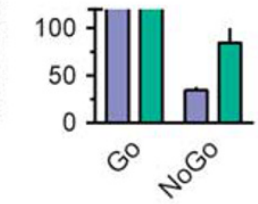

d

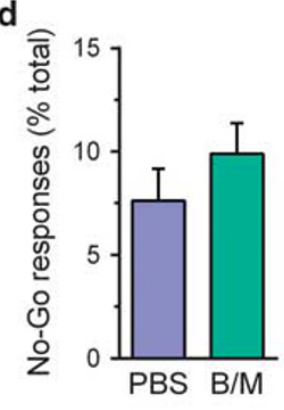

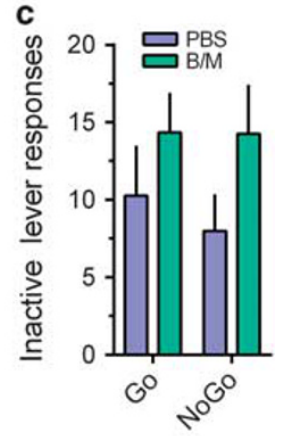

Figure 5 Acquisition of the discrimination between reinforced and non-reinforced intervals in a Go-NoGo task in rats responding for sucrose (a). Effects of $\mathrm{LHb}$ inhibition on active (b) or inactive (c) lever responses in a Go-NoGo task for sucrose. Effects of LHb inhibition on the percentage of active lever responses during the NoGo intervals. All data are mean \pm SEM $(n=1 \mathrm{I})$.

neurons demonstrated either biphasic outward-inward $I_{\text {hold }}$ responses to Oxo-M (34.4\%; Figure 4a and b), consistent with initial hyperpolarization followed by depolarization of the membrane potential, or they showed monophasic outward $I_{\text {hold }}$ responses $(9.4 \%)$, consistent with hyperpolarization (Figure $4 \mathrm{a}$ and $\mathrm{b}$ ). The remaining neurons showed no response to Oxo-M (6.2\%, Figure 4a and b). In additional experiments, the depolarizing outward currents were completely blocked by the $\mathrm{mACh}$ receptor antagonist scopolamine $(10 \mu \mathrm{M}$; Figure $4 \mathrm{c})$. Collectively, these data indicate that the majority $(84.4 \%)$ of LHb neurons are depolarized by $\mathrm{mACh}$ receptor activation, and this may account for the ability of scopolamine to disrupt NoGo responding for cocaine in vivo.

\section{Experiment 5. LHb Inhibition Does Not Impair Go- NoGo Responding for Sucrose Reinforcement}

To determine whether disrupted Go-NoGo performance by $\mathrm{LHb}$ inactivation is specific to responding for cocaine, we examined its effect in animals trained in a Go-NoGo task for sucrose reward. Rats significantly decreased the percentage of non-reinforced sucrose-seeking responses during NoGo intervals from $17.4 \%$ of total responses to $9.0 \%$ over 12 sessions $\left(\mathrm{F}_{(11,110)}=3.64, p=0.021\right.$, one-way ANOVA, Figure 5a). However, LHb inhibition with $\mathrm{B} / \mathrm{M}$ did not significantly alter the number of responses during NoGo periods in these sucrose-trained animals (main effect of $\mathrm{LHb}$ infusions, $\mathrm{F}_{(1,10)}=3.7, \quad p=0.08$, two-way ANOVA, Figure $5 \mathrm{~b}$ ). Moreover, there was also no change in responding during Go intervals during these infusions (Go-NoGo interval $\times \mathrm{LHb}$ infusion interaction, $\mathrm{F}_{(1,10)}=1.92, p=0.19$, two-way ANOVA, Figure 5b). As a result, LHb inactivation did not significantly alter the percentage of responses during the NoGo intervals (PBS = 7.6, $4.2-11.1 ; \mathrm{B} / \mathrm{M}=9.9,6.6-13.9$, mean and $95 \%$ confidence intervals; $t_{(10)}=1.37, p=0.20$, paired $t$-test, Figure $5 \mathrm{~d}$ ). There was also no effect of $\mathrm{LHb}$ inactivation on inactive lever responses (main LHb infusion effect, $\mathrm{F}_{(1,10)}=4.24, p=0.07$, two-way ANOVA, Figure $5 \mathrm{c}$ ), and no interval selectivity (Go-NoGo interval $\times \mathrm{LHb}$ infusion interaction, $\mathrm{F}_{(1,10)}=0.44, p=0.52$, non-significant, twoway ANOVA, Figure 5c). Therefore, unlike Go-NoGo responding for cocaine, $\mathrm{LHb}$ inhibition did not alter this discrimination for sucrose reinforcement.

\section{DISCUSSION}

Here we examine involvement of the LHb in the control of cocaine seeking using several behavioral models. LHb inhibition did not alter the motivation to seek and selfadminister cocaine measured by PR schedule break points nor with seeking responses in a seeking/taking chained schedule of cocaine reinforcement. Similarly, LHb inhibition did not alter punished suppression of cocaine seeking using foot shock administered either after the seeking response or during receipt of the drug. This distinction is important as coincident delivery of reward and punishment can diminish the effectiveness of punishment (Dickinson and Pearce, 1976). As the LHb is involved in behavioral responses to negative outcomes, prediction errors (Hong et al, 2011; Matsumoto and Hikosaka, 2007, 2009), and other aversive events (Stamatakis and Stuber, 2012), the lack of an effect of $\mathrm{LHb}$ inhibition on punished responding for cocaine in our study is somewhat surprising. However, our results agree with another study demonstrating that the LHb is not 
involved in punished suppression of responding for food reinforcement (Jean-Richard Dit Bressel and McNally, 2014). Thus the LHb may participate in signaling negative outcomes but may not be essential for punishment-associated avoidance behavior.

Despite the lack of involvement of the LHb in the motivation to seek cocaine and punished suppression of this behavior, we found that it is involved in withholding responses for cocaine in a Go-NoGo discrimination task. Importantly, rats highly trained to make this discrimination continued to seek cocaine when LHb activity was inhibited, despite its signaled non-availability. This change in behavior did not result from increased cocaine-evoked locomotor activity (Gifuni et al, 2012; Gill et al, 2013; Jean-Richard Dit Bressel and McNally, 2014; Lecourtier et al, 2008), as increased cocaine seeking after LHb inhibition was limited to NoGo intervals, with no change observed during the Go intervals when cocaine is received. Also, reversing the order of Go-NoGo periods did not prevent deficits in response inhibition during the first NoGo interval, prior to cocaine exposure. Moreover, the lack of a selective increase in NoGo responses for sucrose also argues against generalized increases in activity as the explanation for these effects of LHb inhibition on NoGo responding.

Go-NoGo tasks are used to measure action inhibition and impulsiveness in humans and animals (Anker et al, 2008; Dougherty and Bjork, 2003; Lane et al, 2007; McDonald et al, 2003; Paine and Olmstead, 2004), although it is also argued that deficits in performance on these tasks may reflect impairments in attention to and discrimination of stimuli defining the Go-NoGo intervals (Eagle et al, 2008). However, $\mathrm{LHb}$ inactivation does not impair performance in operant tasks where subjects must choose between responses associated with reward size (Stopper and Floresco, 2013) or punishment (Jean-Richard Dit Bressel and McNally, 2014) or reward discrimination in a Y-maze (Baker et al, 2015). Interestingly, intact $\mathrm{LHb}$ function appears necessary for appropriate response choice during more challenging cognitive tasks, such as repeated probabilistic reversal learning, or probabilistic discounting tasks, when repeated evaluations of reward outcomes and adjusted responses are required (Baker et al, 2015; Stopper and Floresco, 2013). As the Go-NoGo task is argued to also include a choice component (Eagle et al, 2008), and the rats in our study were required to evaluate the presence or absence of an environmental cue to respond appropriately within the same session, the LHb inhibitioninduced deficits in the task may result from an impairment in the ability to adjust response selection.

However, LHb inhibition did not impair performance in the Go-NoGo task when sucrose was used to reinforce behavior, suggesting that LHb inhibition does not lead to perceptual or attentional deficits nor to impaired discrimination or response selection in this task. Instead, the evidence favors the interpretation that LHb inhibition impaired the ability to withhold responses in cocaine-experienced rats. This also agrees with a previous study demonstrating that habenular lesions increase premature responding in a fivechoice serial reaction time task, another measure of impulse control (Lecourtier and Kelly, 2005).

To determine which $\mathrm{LHb}$ neuronal pathways modulate Go-NoGo performance for cocaine, we examined the effects of blockers of several neurotransmitter systems. We found that intra-LHb blockade of glutamate receptors did not alter Go-NoGo behavior nor did infusion of the non-selective DA receptor antagonist flupenthixol. Similarly, although serotonergic inputs can excite $\mathrm{LHb}$ neurons via $5-\mathrm{HT}_{2}$ or $5-\mathrm{HT}_{3}$ receptors (Zuo et al, 2016), we found that the antagonists ritanserin and ondansetron failed to alter NoGo cocaine seeking. The $\mathrm{LHb}$ receives $\mathrm{ACh}$ inputs from the dorsolateral tegmentum (Satoh and Fibiger, 1986), the basal forebrain (Herkenham and Nauta, 1977) and the entopeduncular nucleus (Kha et al, 2000; Moriizumi and Hattori, 1992), prompting our examination of a role for $\mathrm{ACh}$ in the Go-NoGo cocaine task. We found that $\beta_{4}$-subunit-containing $\mathrm{nACh}$ receptors are not involved in regulating Go-NoGo cocaine seeking, as the antagonist mecamylamine did not alter this behavior. However, intra-LHb infusion of the $\mathrm{mACh}$ receptor antagonist scopolamine increased cocaineseeking responses during NoGo periods, in a manner that was indistinguishable from the effects of B/M. Although data regarding $\mathrm{mACh}$ receptor function in the $\mathrm{LHb}$ are scarce, acetylcholinesterase inhibitors can increase LHb glucose metabolism via $\mathrm{mACh}$ receptor activation (Bassant et al, 1993), and M2 and M5 mACh receptor mRNA is detected at high and moderate levels in the LHb, respectively (Vilaró et al, 1990, 1992). In electrophysiological studies, we also find that the mACh agonist Oxo-M generates either inward depolarizing or biphasic hyperpolarizing-depolarizing currents in most $\mathrm{LHb}$ neurons and that this is blocked by scopolamine. Together, these in vitro and in vivo pharmacological studies suggest that activation of $\mathrm{mACh}$ receptors excites neurons in the LHb, and this is involved in regulating impulsive responding for cocaine in the Go-NoGo task.

Cocaine has complex effects on LHb neuron activity, with some cells demonstrating excitation or inhibition upon cocaine exposure (Zhang et al, 2013). Interestingly, some LHb neurons show biphasic responses to cocaine, characterized by early inhibition and delayed excitation, and this pattern temporally correlates with behavioral shifts in cocaine rewarding and aversive effects (Jhou et al, 2013). This has inspired the hypothesis that the LHb mediates cocaine's acute aversive effects (Jhou et al, 2013), as well as the negative, depression-like, emotional state associated with cocaine withdrawal (Meye et al, 2015). However, LHb involvement in cocaine seeking is relatively unexplored. One study finds that electrical stimulation of the LHb increases or decreases operant responding for cocaine, depending on the frequency of the stimulation (Friedman et al, 2010). However, as this was also observed in responding for sucrose reward, it is not selective for cocaine (Friedman et al, 2010). These authors also report that LHb lesions do not alter cocaine responding but impair extinction of cocaine seeking. In contrast, another study reports no effect of LHb inactivation on extinction or cue-induced reinstatement of cocaine seeking (Gill et al, 2013), which agrees with unpublished data from our laboratory.

Go-NoGo self-administration tasks are used to model loss of control over drug intake (Belin et al, 2008; DerocheGamonet et al, 2004) and loss of impulse control in food reinforcement (Anker et al, 2008; Paine and Olmstead, 2004; Paine et al, 2003). Moreover, impulsivity is a trait associated with the development of addictive behavior (Anker et al, 2009; Belin et al, 2008; Economidou et al, 2009; de Wit, 2009), and the development of an addictive behavioral phenotype in rats 
is predicted by early increased responding when the drug is unavailable (Deroche-Gamonet and Piazza, 2014). In this context, our findings suggest that the LHb is involved in the withholding of responses for cocaine and that experience with this drug diminishes this control (de Wit, 2009). However, the inability to withhold responses following $\mathrm{LHb}$ inhibition does not appear to extend to sucrose self-administration, suggesting an impairment associated specifically with cocaine seeking. In this regard, we found that rats responding for sucrose acquired the discrimination between Go and NoGo periods more quickly than those trained for cocaine (compare Figure 1f and Figure 5a), as they display much lower responding during initial NoGo intervals (17\% NoGo responses for sucrose vs $51 \%$ for cocaine). Moreover, the sucrose-trained animals maintain lower levels of responding during NoGo intervals after the task has been learned (7-9\% vs $15-20 \%$, respectively). This is consistent with a greater difficulty in withholding responses for cocaine $v s$ sucrose. This disparity may be related to prior exposure to cocaine, as earlier studies show that the bundle of LHb efferent axons known as the fasciculus retroflexus degenerates after high-dose, extended access psychostimulant exposure (Ellison, 1992; Lax et al, 2013) and that LHb metabolic activity decreases following acute and chronic exposure to cocaine (Hammer and Cooke, 1994; London et al, 1986). Thus it is possible that the participation of the $\mathrm{LHb}$ in controlling responding for cocaine may be compromised by limited cocaine exposure, such as that used in our study, and that more extensive exposure may lead to further reductions in LHb output to downstream brain areas that are involved in regulating drug seeking. Thus damage to LHb efferents by psychostimulants may limit the inhibitory control that this brain structure exerts over drug intake, thereby driving compulsive drug seeking observed in addiction.

\section{FUNDING AND DISCLOSURE}

This work was supported by the U.S.A. Department of Health and Human Services, National Institutes of Health, National Institute on Drug Abuse, Intramural Research Program. The authors declare no conflict of interest.

\section{ACKNOWLEDGMENTS}

We thank Dr Yavin Shaham and Dr Geoffrey Schoenbaum for providing feedback on the manuscript.

\section{REFERENCES}

Anker JJ, Gliddon LA, Carroll ME (2008). Impulsivity on a Go/No-go task for intravenous cocaine or food in male and female rats selectively bred for high and low saccharin intake. Behav Pharmacol 19: 615-629.

Anker JJ, Perry JL, Gliddon LA, Carroll ME (2009). Impulsivity predicts the escalation of cocaine self-administration in rats. Pharmacol Biochem Behav 93: 343-348.

Baker PM, Oh SE, Kidder KS, Mizumori SJ (2015). Ongoing behavioral state information signaled in the lateral habenula guides choice flexibility in freely moving rats. Front Behav Neurosci 9: 295.

Bassant MH, Jazat F, Lamour Y (1993). Tetrahydroaminoacridine and physostigmine increase cerebral glucose utilization in specific cortical and subcortical regions in the rat. J Cereb Blood Flow Metab 13: 855-864.

Belin D, Mar AC, Dalley JW, Robbins TW, Everitt BJ (2008). High impulsivity predicts the switch to compulsive cocaine-taking. Science 320: 1352-1355.

Belin-Rauscent A, Fouyssac M, Bonci A, Belin D (2016). How preclinical models evolved to resemble the diagnostic criteria of drug addiction. Biol Psychiatry 79: 39-46.

Christoph GR, Leonzio RJ, Wilcox KS (1986). Stimulation of the lateral habenula inhibits dopamine-containing neurons in the substantia nigra and ventral tegmental area of the rat. J Neurosci 6: 613-619.

Deroche-Gamonet V, Belin D, Piazza PV (2004). Evidence for addiction-like behavior in the rat. Science 305: 1014-1017.

Deroche-Gamonet V, Piazza PV (2014). Psychobiology of cocaine addiction: Contribution of a multi-symptomatic animal model of loss of control. Neuropharmacology 76 Pt B: 437-449.

Dickinson A, Pearce J (1976). Preference and response suppression under different correlations between shock and a positive reinforcer in rats. Learn Motiv 7: 66-85.

Dougherty DM, Bjork JM (2003). Behavioral impulsivity paradigms: a comparison in hospitalized adolescents with disruptive behavior disorders. J Child Psychiatry 44: 1145-1157.

Eagle DM, Bari A, Robbins TW (2008). The neuropsychopharmacology of action inhibition: cross-species translation of the stop-signal and go/no-go tasks. Psychopharmacology (Berl) 199: 439-456.

Economidou D, Pelloux Y, Robbins TW, Dalley JW, Everitt BJ (2009). High impulsivity predicts relapse to cocaine-seeking after punishment-induced abstinence. Biol Psychiatry 65: 851-856.

Ellison G (1992). Continuous amphetamine and cocaine have similar neurotoxic effects in lateral habenular nucleus and fasciculus retroflexus. Brain Res 598: 353-356.

Friedman A, Lax E, Dikshtein Y, Abraham L, Flaumenhaft Y, Sudai E et al (2010). Electrical stimulation of the lateral habenula produces enduring inhibitory effect on cocaine seeking behavior. Neuropharmacology 59: 452-459.

Gifuni AJ, Jozaghi S, Gauthier-Lamer A-CC, Boye SM (2012). Lesions of the lateral habenula dissociate the reward-enhancing and locomotor-stimulant effects of amphetamine. Neuropharmacology 63: 945-957.

Gill MJ, Ghee SM, Harper SM, See RE (2013). Inactivation of the lateral habenula reduces anxiogenic behavior and cocaine seeking under conditions of heightened stress. Pharmacol Biochem Behav 111: 24-29.

Good CH, Wang H, Chen Y-HH, Mejias-Aponte CA, Hoffman AF, Lupica CR (2013). Dopamine D4 receptor excitation of lateral habenula neurons via multiple cellular mechanisms. J Neurosci 33: $16853-16864$.

Hammer RP, Cooke ES (1994). Gradual tolerance of metabolic activity is produced in mesolimbic regions by chronic cocaine treatment, while subsequent cocaine challenge activates extrapyramidal regions of rat brain. J Neurosci 14: 4289-4298.

Herkenham M, Nauta WJ (1977). Afferent connections of the habenular nuclei in the rat. A horseradish peroxidase study, with a note on the fiber-of-passage problem. J Comp Neurol 173: 123-146.

Hikosaka O (2010). The habenula: from stress evasion to valuebased decision-making. Nat Rev Neurosci 11: 503-513.

Hong S, Jhou TC, Smith M, Saleem KS, Hikosaka O (2011). Negative reward signals from the lateral habenula to dopamine neurons are mediated by rostromedial tegmental nucleus in primates. J Neurosci 31: 11457-11471.

Jean-Richard Dit, Bressel P, McNally GP (2014). The role of the lateral habenula in punishment. PLoS One 9: e111699.

Jhou TC, Fields HL, Baxter MG, Saper CB, Holland PC (2009). The rostromedial tegmental nucleus (RMTg), a GABAergic afferent to midbrain dopamine neurons, encodes aversive stimuli and inhibits motor responses. Neuron 61: 786-800.

Jhou TC, Good CH, Rowley CS, Xu S-PP, Wang H, Burnham NW et al (2013). Cocaine drives aversive conditioning via delayed 
activation of dopamine-responsive habenular and midbrain pathways. J Neurosci 33: 7501-7512.

Ji H, Shepard PD (2007). Lateral habenula stimulation inhibits rat midbrain dopamine neurons through a GABA(A) receptormediated mechanism. J Neurosci 27: 6923-6930.

Kha H, Finkelstein D, Pow D, Lawrence A, Horne M (2000). Study of projections from the entopeduncular nucleus to the thalamus of the rat. J Comp Neurol 426: 366-377.

Lane SD, Moeller FG, Steinberg JL, Buzby M, Kosten TR (2007). Performance of cocaine dependent individuals and controls on a response inhibition task with varying levels of difficulty. $A m \mathrm{~J}$ Drug Alcohol Abuse 33: 717-726.

Lax E, Friedman A, Croitoru O, Sudai E, Ben-Moshe H, Redlus L et al (2013). Neurodegeneration of lateral habenula efferent fibers after intermittent cocaine administration: implications for deep brain stimulation. Neuropharmacology 75: 246-254.

Lecca S, Meye FJ, Mameli M (2014). The lateral habenula in addiction and depression: an anatomical, synaptic and behavioral overview. Eur J Neurosci 39: 1170-1178.

Lecourtier L, Defrancesco A, Moghaddam B (2008). Differential tonic influence of lateral habenula on prefrontal cortex and nucleus accumbens dopamine release. Eur J Neurosci 27: 1755-1762.

Lecourtier L, Kelly PH (2005). Bilateral lesions of the habenula induce attentional disturbances in rats. Neuropsychopharmacology 30: 484-496.

Lecourtier L, Kelly PH (2007). A conductor hidden in the orchestra? Role of the habenular complex in monoamine transmission and cognition. Neurosci Biobehav Rev 31: 658-672.

London E, Wilkerson G, Goldberg S, Risner M (1986). Effects of L-cocaine on local cerebral glucose utilization in the rat. Neurosci Lett 68: 73-78.

Maroteaux M, Mameli M (2012). Cocaine evokes projection-specific synaptic plasticity of lateral habenula neurons. J Neurosci 32: 12641-12646.

Matsumoto M, Hikosaka O (2007). Lateral habenula as a source of negative reward signals in dopamine neurons. Nature 447: 1111-1115.

Matsumoto M, Hikosaka O (2009). Representation of negative motivational value in the primate lateral habenula. Nat Neurosci 12: 77-84.

McDonald J, Schleifer L, Richards JB, de Wit H (2003). Effects of THC on behavioral measures of impulsivity in humans. Neuropsychopharmacology 28: 1356-1365.

Mello Cruz AP, de, Pinheiro G, Alves SHH, Ferreira G, Mendes M, Faria L et al (2005). Behavioral effects of systemically administered MK-212 are prevented by ritanserin microinfusion into the basolateral amygdala of rats exposed to the elevated plus-maze. Psychopharmacology (Berl) 182: 345-354.

Meye FJ, Valentinova K, Lecca S, Marion-Poll L, Maroteaux MJ, Musardo S et al (2015). Cocaine-evoked negative symptoms require AMPA receptor trafficking in the lateral habenula. Nat Neurosci 18: 376-378.

Moriizumi T, Hattori T (1992). Choline acetyltransferaseimmunoreactive neurons in the rat entopeduncular nucleus. Neuroscience 46: 721-728.

Murray JE, Belin D, Everitt BJ (2012). Double dissociation of the dorsomedial and dorsolateral striatal control over the acquisition and performance of cocaine seeking. Neuropsychopharmacology 37: 2456-2466.

Olmstead MC, Parkinson JA, Miles FJ, Everitt BJ, Dickinson A (2000). Cocaine-seeking by rats: regulation, reinforcement and activation. Psychopharmacology (Berl) 152: 123-131.

Paine TA, Dringenberg HC, Olmstead MC (2003). Effects of chronic cocaine on impulsivity: relation to cortical serotonin mechanisms. Behav Brain Res 147: 135-147.

Paine TA, Olmstead MC (2004). Cocaine disrupts both behavioural inhibition and conditional discrimination in rats. Psychopharmacology (Berl) 175: 443-450.
Pelloux Y, Everitt BJ, Dickinson A (2007). Compulsive drug seeking by rats under punishment: effects of drug taking history. Psychopharmacology (Berl) 194: 127-137.

Richardson NR, Roberts DC (1996). Progressive ratio schedules in drug self-administration studies in rats: a method to evaluate reinforcing efficacy. J Neurosci Methods 66: 1-11.

Santini E, Sepulveda-Orengo M, Porter JT (2012). Muscarinic receptors modulate the intrinsic excitability of infralimbic neurons and consolidation of fear extinction. Neuropsychopharmacology 37: 2047-2056.

Satoh K, Fibiger HC (1986). Cholinergic neurons of the laterodorsal tegmental nucleus: efferent and afferent connections. J Comp Neurol 253: 277-302.

Stamatakis AM, Stuber GD (2012). Activation of lateral habenula inputs to the ventral midbrain promotes behavioral avoidance. Nat Neurosci 15: 1105-1107.

Stopper CM, Floresco SB (2013). What's better for me? Fundamental role for lateral habenula in promoting subjective decision biases. Nat Neurosci 17: 33-35.

Sun W, Akins C, Mattingly A, Rebec G (2005). Ionotropic glutamate receptors in the ventral tegmental area regulate cocaine-seeking behavior in rats. Neuropsychopharmacology 30: 2073-2081.

Sutherland RJ (1982). The dorsal diencephalic conduction system: a review of the anatomy and functions of the habenular complex. Neurosci Biobehav Rev 6: 1-13.

Tuerke KJ, Limebeer CL, Fletcher PJ, Parker LA (2012). Double dissociation between regulation of conditioned disgust and taste avoidance by serotonin availability at the 5-HT(3) receptor in the posterior and anterior insular cortex. $J$ Neurosci 32: 13709-13717.

Vanderschuren L, Ahmed S (2013). Animal studies of addictive behavior. Cold Spring Harb Perspect Med 3: a011932.

Vanderschuren LJMJ, Everitt BJ (2004). Drug seeking becomes compulsive after prolonged cocaine self-administration. Science 305: 1017-1019.

Velasquez KM, Molfese DL, Salas R (2014). The role of the habenula in drug addiction. Front Hum Neurosci 8: 174.

Vilaró MT, Palacios JM, Mengod G (1990). Localization of m5 muscarinic receptor mRNA in rat brain examined by in situ hybridization histochemistry. Neurosci Lett 114: 154-159.

Vilaró MT, Wiederhold KH, Palacios JM, Mengod G (1992). Muscarinic M2 receptor mRNA expression and receptor binding in cholinergic and non-cholinergic cells in the rat brain: a correlative study using in situ hybridization histochemistry and receptor autoradiography. Neuroscience 47: 367-393.

Wickham R, Solecki W, Rathbun L, McIntosh JM, Addy NA (2013). Ventral tegmental area $\alpha 6 \beta 2$ nicotinic acetylcholine receptors modulate phasic dopamine release in the nucleus accumbens core. Psychopharmacology (Berl) 229: 73-82.

de Wit $\mathrm{H}$ (2009). Impulsivity as a determinant and consequence of drug use: a review of underlying processes. Addict Biol 14: $22-31$.

Zapata A, Minney VL, Shippenberg TS (2010). Shift from goaldirected to habitual cocaine seeking after prolonged experience in rats. $J$ Neurosci 30: 15457-15463.

Zhang C-XX, Zhang H, Xu H-YY, Li M-XX, Wang S (2013). The lateral habenula is a common target of cocaine and dexamethasone. Neurosci Lett 555: 12-17.

Zuo W, Chen L, Wang L, Ye J-HH (2013). Cocaine facilitates glutamatergic transmission and activates lateral habenular neurons. Neuropharmacology 70: 180-189.

Zuo W, Zhang Y, Xie G, Gregor D, Bekker A, Ye J-HH (2016). Serotonin stimulates lateral habenula via activation of the post-synaptic serotonin $2 / 3$ receptors and transient receptor potential channels. Neuropharmacology 101: 449-459.

Supplementary Information accompanies the paper on the Neuropsychopharmacology website (http://www.nature.com/npp) 